\title{
Leveraged Bootstrap Test of Volatility: A Novel Approach to the Energy Consumption and Economic Growth Puzzle
}

\author{
Kuo-Hao Lee ${ }^{1}$, Jonathan Ohn ${ }^{1} \&$ Evren Eryilmaz ${ }^{2}$ \\ ${ }^{1}$ Department of Finance, Zeigler College of Business, Bloomsburg University of Pennsylvania, USA \\ 2 Department of Management Information Systems, College of Business Administration, California State \\ University Sacramento, USA \\ Correspondence: Kuo-Hao Lee, Department of Finance, Zeigler College of Business, Bloomsburg University of \\ Pennsylvania, Bloomsburg, PA17815, USA. E-mail: klee@bloomu.edu
}

Received: April 15, 2015

doi:10.5539/ijef.v9n9p117

\begin{abstract}
The main purpose of this research is to examine the causal relationship between the Energy industry and nine other industries by use of volatility instead of returns. Existing literatures find a causal relationship by use of stock returns, however, we find that using volatility reveals a causal relationship that might not otherwise be revealed through returns alone. Since the existing literature shows that volatility of stock prices is informative, we apply a Granger causality test by use of a leveraged bootstrap test developed by Hacker and Hatemi (2006) to investigate the causal behavior of the volatility. Our results show that volatility of the Energy industry causes volatility in two other industries- Industrials and Health Care. Also, the Energy industry market is affected by the Materials, Consumer Staples and Utilities industries. This finding is substantially different from the findings of previous research, and provides a novel approach to analyzing and solving the energy consumption and economic growth puzzle.
\end{abstract}

Keywords: Granger causality, bootstrap, volatility, S\&P 500

\section{Introduction}

There are many literatures, include the empirical tests and theoretical arguments focus on the relationship between energy consumption and economic growth, have found the role of the energy industry in stimulating economic growth by identifying the direction in-which a causal relationship is directed between these two variables. These literatures rely on returns to identify a causal relationship between energy consumption and economic growth. The foundations of these studies are derived, in large, from fluctuations, in returns, between Oil/Natural Gas prices, and economic growth (Ozturk, 2010). Lately, there have emerged recent literature on the disjoining of Oil and Natural Gas prices post the 2009 discovery of new method of extraction of Natural Gas from Shale (Erdos, 2012). We believe that because of this fundamental change in the energy industry, aggregate overall returns in energy have been stabilized, although the disaggregate pricing of individual energy sources have fluctuated wildly. Therefore, we believe that relying on returns to identify a causal relationship between energy consumption and economic growth is not sufficient. We find that using volatility (as a proxy to market information) reveals a causal relationship that might not otherwise be revealed through returns alone. The use of volatility instead of returns incorporates the nuances in price fluctuations that might not have been captured in returns. This finding is important for investors by providing an alternative method to measure risk that might not have previously been considered.

Gross (2012), finds evidence of a unidirectional long-run Granger causality in the commercial sector from economic growth to energy consumption, as well as evidence for bi-directional long-run Granger causality in the transport sector. Recent studies find a significant reaction of U.S. real stock returns to an oil price shocks. Kilian and Park (2009) finds that the demand and supply shocks driving the global crude oil market jointly accounted for $22 \%$ of the long-run variation in U.S. real stock returns. The responses of industry-specific U.S. stock returns to demand and supply shocks in the crude oil market are consistent with accounts of the transmission of oil price shocks that emphasize the reduction in domestic final demand. Furthermore, a recent study by Oberndorfer (2009) finds that oil price hikes negatively impacted stock returns of European utilities. Oberndorfer also finds that coal price developments affect the stock returns of European utilities; however, this effect is small compared 
to the oil price impacts.

Some research, on the other hand, find that there is no significant impact of oil prices on the stock market. Cong, Wei, Jiao, and Fan (2008) investigated the relationship between oil price shocks and the Chinese stock market using multivariate vector auto-regression and finds that oil price shocks do not show a statistically significant impact on the real stock returns for most Chinese stock market indices except for the manufacturing index and some oil companies. Apergis and Miller (2009) investigates how explicit oil price changes affect stock-market returns in a sample of eight countries - Australia, Canada, France, Germany, Italy, Japan, the United Kingdom, and the United States. They find that international stock market returns generally do not respond, in large, to oil market shocks.

The majority of current literatures solely apply returns of stocks to test the connections and relations between stocks prices and market information. However, based on varied prior researches, we consider that the investors will only receive a part of market information on stocks if they just simply looking into stocks returns. Volatility is used as a fine indicator of present and future information based on conclusions from previous studies. By constructing a proper diversified investment portfolio, sophisticated investors could minimize and further eliminate the unsystematic risk. Under traditional Capital Asset Pricing Model (CAPM), the systematic risk no doubt becomes the only consideration factor on influencing asset prices. However, more recent empirical researches have found that the idiosyncratic risks of individual stock was in fact the decisive and critical factor impact the most on the risk premium of stock investment portfolio. This conclusion is different from the traditional finance believe which built from CAPM that the systematic risk is the sole element that would generate the effect on returns. We consider the notion that many previous literatures have eluded to, which is, that volatility was informative as well. By implementing volatility to further explore the behavior of information travelling, we believe it will create a sturdier research method than simply by using stock returns.

A recent study by Campbell, Lettau, Malkiel, and Xu (2001) attempted to break through the traditional path of returns base calculation empirical test. By adopting a disaggregated methodology, they effectively distinguished the stock return's volatility into three separated levels: market volatility, industry volatility, and firm's idiosyncratic volatility. Another decomposition method and a disaggregated approach method were applied by $\mathrm{Xu}$ and Malkiel in their 2003 research. They decomposed volatility of stock returns into different categories as idiosyncratic form and systematic form. Xu and Malkiel concluded in their research that private information from the corporation could be reflected to the price of its stock more efficiently under the situation that a higher percentage of the company's stock was held by the institutional investors. Hatemi and Irandoust (2011) suggested an interaction that the returns will cause the volatility positively while the volatility causes returns negatively.

In order to depart from the previous researches, we further apply the volatility concept to examine the relationship between Energy Industry and other nine industries.

\section{Data and Methodology}

The data used in our research include four hundred and sixteen firms from S\&P 500 list. We adopted the data of their final quarterly earnings announcements of year 2010 released on December $31^{\text {st }}$. We also applied the data in the range of twenty five days before and twenty days after December $31^{\text {st }}$. That would make our research period located from November $23^{\text {th }}$ to January $31^{\text {st }}, 2012$.

Due to the nature of our research, namely the use of high frequency data, we considered the research approach method outlined in Campbell, Lettau, Malkiel, and Xu (2001) would be the more proper practice for our study. According to Braandt, Brav, Graham, and Kumar (2010), we used the calculation format for each stock $\mathrm{j}$ that belongs to industry I on day $t$, the intraday firm residual could be calculated by deducting the industry-i return:

$$
\varepsilon_{i j s t}=r_{i j s t}-r_{i s t}
$$

where $r_{i j s t}$ is the return of $s^{\text {th }} 5$-minutes interval on day $t$ of stock $j$ that belongs to industry $i$ and $r_{i s t}$ is the valued weighted return of industry $I$ in $s^{\text {th }} 5$-minutes interval on day $t$.

We then computed the day-t idiosyncratic volatility $\left(\sigma_{\mathrm{ijt}}^{\mathrm{id}}\right)$ of stock $\mathrm{j}$ in industry I by

$$
\sigma_{i j t}^{i d}=\sqrt{\sum_{s} \varepsilon_{i j s t}^{2}}
$$

Industry volatility:

We used the daily idiosyncratic volatility for estimations of all stocks. The value weighted average volatility for each industry we calculated will be as: 


$$
\sigma_{i t}=\sum_{j} w_{i j, t-1} \sigma_{i j t}^{i d}
$$

where $\mathrm{w}_{\mathrm{ijt}}$ is the day- $\mathrm{t}$ weight of stock $\mathrm{j}$ belonging to industry-i.

Since we have computed the volatility of every industry, we then follow up using of a leveraged bootstrap test built up Hacker and Hatemi-J (2006) to investigate for Granger causality relationship.

$$
\sigma_{t}=v+A_{1} \sigma_{t-1}+\cdots+A_{p} \sigma_{t-p}+e_{t}
$$

where $\sigma$ is a two dimensional vector of volatility from two industries. Based on the model Hatemi $(2003,2008)$ formed, we defined the information criterion as:

$$
H J C=\ln \left(\operatorname{det} \widehat{\Omega}_{j}\right)+j\left(\frac{n^{2} \ln T+2 n^{2} \ln (\ln T)}{2 T}\right), j=0, \ldots, p .
$$

where $\operatorname{det} \widehat{\Omega}_{j}$ represent the determinant of the estimated ML variance variance-covariance matrix of the residuals in the $\operatorname{VAR}(\mathrm{j})$ model. $\mathrm{N}$ is denoted as the number of the variables and $\mathrm{T}$ is the sample size.

The null hypothesis that $k$ th element of $\sigma_{\mathrm{t}}$ does not Granger-cause the $d$ th element of $\sigma_{\mathrm{t}}$ is defined as:

$H_{0}$ : the row $d$, column $k$ element in $\mathrm{A}_{\mathrm{r}}$ equals 0 for $\mathrm{r}=1, \ldots, \mathrm{p}$.

We applied a Wald test listed below to examine the null hypothesis:

$Y:=\left(\sigma_{1}, \ldots, \sigma_{T}\right)(n \times T)$ martix $, D:\left(v, A_{1}, \ldots, A_{p}\right)(n \times(1+n \times p))$ matrix,

$Z_{t}:=\left[\begin{array}{c}1 \\ \sigma_{t} \\ \sigma_{t-1} \\ \ldots \\ \sigma_{t-p}\end{array}\right]((1+n \times p) \times 1)$ matrix, for $t=1, \ldots T$.

$Z:=\left(Z_{0}, \ldots, Z_{T-1}\right)((1+n \times p) \times T)$ matrix, and $\varepsilon:=\left(e_{1}, \ldots, e_{T}\right)(n \times T)$ matrix,

where $\mathrm{n}$ is the number of variables, which is two in our case, and $\mathrm{T}$ is the sample size. By using these denotations, the $\operatorname{VAR}(\mathrm{p})$ model can be reformulated as:

$$
Y=D Z+\varepsilon
$$

Second, the non-Granger causality null hypothesis could be stated as:

$$
H_{0}: C \beta=0
$$

The following Wald test statistics will be used to test the null hypothesis:

$$
\text { Wald }=(C \beta)^{\prime}\left[C\left(\left(Z^{\prime} Z\right)^{-1} \otimes S_{U}\right) C^{\prime}\right]^{-1}(C \beta) \sim \chi_{p}^{2},
$$

where $\beta=\operatorname{vec}(D)$ and $\operatorname{vec}$ is the column-stacking operator; the notation $\otimes$ represents the Kronecker product (that is, element by all elements matrix multiplication), and $\mathrm{C}$ is a $(p \times n)(1+p \times n)$ indicator matrix with elements consisting of ones and zeros. The elements in each row of $C$ takes a value of one if related parameter in $\beta$ is zero under the null hypothesis, and they take a value of zero if there is no such restriction under the null. $S_{U}$ represents the variance-covariance matrix of the unrestricted VAR model. That is, $S_{U}=\left(\hat{\varepsilon}^{\prime}{ }_{U} \hat{\varepsilon}_{U}\right) /$ $(T-c)$, where $\mathrm{c}$ is the number of estimated parameters. When the assumption of normality is fulfilled, the Wald test statistics defined above is asymptotically distributed as $\chi^{2}$ with the number of degrees of freedom equal to the number of restrictions under the null hypothesis ( in this case, it will equal to $\mathrm{p}$ ).

We should understand that non-normality and with time-varying volatilities are the major factors that have been usually used to characterize the data of the financial system for emerging markets. Therefore, we will not expect the same level of performance accuracy from Wald test which was based on asymptotic critical values under certain conditions. We executed a newer causality test methodology created by Hacker and Hatemi (2006) in our research. The new method covers and is robust to time-varying volatility as well as non-normality. The following steps below are taken in order to manage the test:

I. Estimate the VAR model using the selected lag order, $\mathrm{p}$, and obtain the estimated residuals $\left(\hat{e}_{t}\right)$.

II. Then, generate the simulated data, denoted by $\sigma_{t}^{*}$, as following:

$$
\sigma_{t}^{*}=\hat{A}_{0}+\hat{A}_{1} \sigma_{t-1}+\cdots+\hat{A}_{p} \sigma_{t-p}+\hat{e}_{t}^{*}
$$

where the circumflex above a variable represents its estimated values. The variable $\hat{e}_{t}^{*}$ is the bootstrapped residuals, which are based on $T$ random draws with replacement from the regressions' modified residuals (to be defined below). To ensure a zero for the expected value of the residuals which means these residuals are mean 
adjusted in every individual draw. As Hacker and Hatemi (2006) suggested that with the aim of having constant variance, we control the raw residuals from the regressions to be modified by using leverages. To further introduced about the notations we used in the study, we elaborated more explicitly below: First, we define $Y_{-p}=\left(\sigma_{1-L}, \ldots, \sigma_{T-p}\right)$ and let $Y_{i,-p}$ be the $i$ th row of $Y_{-p}$. Thus, $Y_{i,-p}$ is defined as a row vector of the lag $\mathrm{p}$ values for variables $\sigma_{i t}$ during the sample period $t=1, \ldots, T$. We then define $V=\left(Y^{\prime}{ }_{-1}, \ldots, Y^{\prime}{ }_{-p}\right)$ and $V_{i}=\left(Y^{\prime}{ }_{i,-1}, \ldots, Y^{\prime}{ }_{i,-p}\right)$ for $i=1,2$. For the equation that generates $\sigma_{1 t}$, the independent variable matrix for the regression is $V_{1}$; this equation is restricted by the null hypothesis non-Granger causality. For the equation that generates $\sigma_{2 t}$, the independent variable matrix for the regression is $V$; this equation is not restricted by the null hypothesis non-Granger causality and includes the lag values of all variables in the VAR model. Now we are now positioned to define the $T \times 1$ leverages vectors for $\sigma_{1 t}$ and $\sigma_{2 t}$ as:

$$
l_{1}=\operatorname{diag}\left(V_{1}\left(V^{\prime}{ }_{1} V_{1}\right)^{-1} V^{\prime}{ }_{1}\right) \text { and } l_{1}=\operatorname{diag}\left(V\left(V^{\prime} V\right)^{-1} V^{\prime}\right) .
$$

These leverages are used to modify the residuals in order to take into account that effect of ARCH. The modified residual for $\sigma_{i t}$ is produced as:

$$
\hat{u}_{i t}^{m}=\frac{\hat{u}_{i t}}{\sqrt{1-l_{i t}}}
$$

where $l_{i t}$ it the element of $l_{i}$, and $\hat{u}_{i t}$ is the raw residual from the regression for $\sigma_{i t}$.

III. Next, We operate the bootstrap simulation ten thousand times and for each simulation we computed the W test statistics. By following this process, we can construct an approximate distribution for the $W$ test statistic. Subsequent to these 10,000 estimations we determine the ( $\alpha$ )th upper quintile of the distribution of the bootstrapped $W$ statistics and find the $\alpha$-level of significant "bootstrap critical values" $\left(c_{\alpha}^{*}\right)$. We followed and conducted the simulations module by adopting Hacker and Hatemi (2009a)'s model written in Gauss.

Finally, we compare the calculated W statistic using the original simulated data (not the data that is generated via bootstrap simulations). If the calculated $\mathrm{W}$ statistics is higher than the bootstrap critical values $c_{\alpha}^{*}$, we then rejected the null hypothesis of non-Granger causality at the $\alpha$-level of significance. An algorithm written in Gauss syntax was used for the simulations conducting.

\section{Empirical Results}

Before testing the causality between the volatility of the Energy industry and the volatility of one of the other industries, both variables were tested for unit roots by using the $\mathrm{Ng}$-Perron test. The results showed that both variables are stationary. As mentioned previously, we applied a bootstrap simulation to calculate the critical numbers for our study from the data distribution that do not require for normality. The results show, in Table 1, that the W statistics computed for the causal effect of volatility from the Energy industry on the Materials industry's volatility is 0.402 . The number is smaller than the estimation of the critical values on each significant level. However, the W statistic calculated for the causal effect of the Materials industry's volatility on the Energy industry's volatility is 6.162 . This number is larger than the estimation of the critical values at the $5 \%$ and $10 \%$ significance levels. The empirical results support the finding that there existed a uni-direction causality between the Energy industry's volatility and Materials industry's volatility. Overall, the observations also demonstrated that there are two other industries include Industrials and Health Care industries are influenced by Energy industry. Also, the Materials, Consumer Staples, and Utilities industries are the ones to affect the Energy industry market. From our test results, the data fail to reject the null hypothesis which stated that there have no significant causal relationship among the Energy industry, Consumer Discretionary, Financials, Information Technology, and Telecommunication Services industries.

\section{Conclusions}

The main objective of this paper is to investigate if there exists causality between the Energy industry and other industries. Given fundamental changes in the Energy industry, such as the evolution of a new method of shale gas and oil extraction, we believed that the traditional method of using returns to find a causal relationship was unreliable. We believe that because of this fundamental change in the energy industry, aggregate overall returns in energy have been stabilized, although the disaggregate pricing of individual energy sources have fluctuated wildly. Therefore, the use of volatility instead of returns in finding a causal relationship incorporates the nuances in price fluctuations that might not have been captured solely in returns. We utilized the Brandt, Brav, Graham, and Kumar (2010) method for volatility in conjunction with a causal relationship test methodology created by Hacker and Hatemi (2006), which is robust to ARCH and non-normality, to compute the causal volatility of four hundred and sixteen firms listed in S\&P 500 firms between the periods of November 23th, 2011 to January 31st, 2012. According to our causality test results, there exists causality of the Energy industry on two other industries, 
Industrials and Health Care. Operating industries and health care facilities require great deals of energy usage which can impact the movements of the Industrials and Health Care industries. We believe that this is the first such finding of a link between these two unique industries, and may elicite further research in finding why such a link exists. Furthermore, the Energy industry market is also affected by the Materials, Consumer Staples and Utilities industries. The positive performance of Materials and Utilities industries can indicate growing demand spending on Energy which might enhance the returns of Energy industry. These findings are substantially different from the findings of previous research, and provides a novel approach to analyzing and solving the energy consumption and economic growth puzzle.

Table 1 . The test result of causality using the leveraged bootstrap test

\begin{tabular}{lcccc}
\hline Null hypothesis & calculated W statistics & \multicolumn{3}{c}{ bootstrap critical value } \\
\hline & & $1 \%$ & $5 \%$ & $10 \%$ \\
Energy $\neq>$ Materials & 0.402 & 7.488 & 4.08 & 2.804 \\
Materials $\neq>$ Energy & $6.162^{* *}$ & 7.672 & 4.263 & 2.903 \\
Energy $\neq>$ Industrials & $4.371^{* *}$ & 7.352 & 4.096 & 2.775 \\
Industrials $\neq>$ Energy & 0.002 & 8.262 & 4.09 & 2.722 \\
Energy $\neq>$ Consumer Discretionary & 1.747 & 7.437 & 4.1 & 2.848 \\
Consumer Discretionary $\neq>$ Energy & 1.757 & 7.309 & 4.156 & 2.938 \\
Energy $\neq>$ Consumer Staples & 0.559 & 7.426 & 4.085 & 2.803 \\
Consumer Staples $\neq>$ Energy & $3.798^{*}$ & 7.189 & 4.1 & 2.928 \\
Energy $\neq>$ Health Care & $3.221^{*}$ & 7.25 & 4.022 & 2.775 \\
Health Care $\neq>$ Energy & 0.058 & 7.388 & 4.17 & 2.912 \\
Energy $\neq>$ Financials & 0.211 & 7.255 & 4.257 & 2.937 \\
Financials $\neq>$ Energy & 0.426 & 8.054 & 4.145 & 2.841 \\
Energy $\neq>$ Information Technology & 2.731 & 7.269 & 4.186 & 2.833 \\
Information Technology $\neq>$ Energy & 1.351 & 6.997 & 4.042 & 2.849 \\
Energy $\neq>$ Telecommunication Services & 1.952 & 7.302 & 4.107 & 2.785 \\
Telecommunication Services $\neq>$ Energy & 0.031 & 7.406 & 4.116 & 2.86 \\
Energy $\neq>$ Utilities & 0.960 & 7.394 & 4.12 & 2.86 \\
Utilities $\neq>$ Energy & $4.003^{* *}$ & 7.612 & 4.258 & 2.949 \\
\hline
\end{tabular}

Note. 1 . Energy $\neq>$ Materials denoted as Energy volatility does not cause Materials volatility. $2 . *$ and $* *$ indicated that the null hypothesis is rejected at $10 \%$ and $5 \%$.

\section{References}

Apergis, N., \& Miller, S. M. (2009). Do structural oil-market shocks affect stock prices? Energy Economics, 31(4), 569-575. https://doi.org/10.1016/j.eneco.2009.03.001

Brandt, M. W., Brav, A., Graham, J. R., \& Kumar, A. (2010). The idiosyncratic volatility puzzle: Time trend or speculative episodes? Review of Financial Studies, 23(2), 863-899. https://doi.org/10.1093/rfs/hhp087

Campbell, J. Y., Lettau, M., Malkiel, B. G., \& Xu, Y. (2001). Have individual stocks become more volatile? An empirical exploration of idiosyncratic risk. The Journal of Finance, 56(1), 1-43. https://doi.org/10.1111/0022-1082.00318

Cong, R. G., Wei, Y. M., Jiao, J. L., \& Fan, Y. (2008). Relationships between oil price shocks and stock market: An empirical analysis from China. Energy Policy, 36(9), 3544-3553. https://doi.org/10.1016/j.enpol.2008.06.006

Erdos, P. (2012). Have Oil and Gas Prices Got Seperated? Energy Policy, 49(76), 707-718. https://doi.org/10.1016/j.enpol.2012.07.022

Gross, C. (2012). Explaining the (non-) causality between energy and economic growth in the U.S. - A multivariate sectoral analysis. Energy Economics, 34(2), 489. https://doi.org/10.1016/j.eneco.2011.12.002

Hacker, R. S., \& Hatemi, J. A. (2006). Tests for causality between integrated variables using asymptotic and bootstrap distributions: Theory and application. Applied Economics, 38(13), 1489-1500. https://doi.org/10.1080/00036840500405763

Hatemi, J. A., \& Irandoust, M. (2011). The dynamic interaction between volatility and returns in the US stock 
market using leveraged bootstrap simulations. Research in International Business and Finance, 25(3), 329-334. https://doi.org/10.1016/j.ribaf.2011.03.001

Hatemi, J. A., \& S. Hacker, R. (2009). Can the LR test be helpful in choosing the optimal lag order in the VAR model when information criteria suggest different lag orders? Applied Economics, 41(9), 1121-1125. https://doi.org/10.1080/00036840601019273

Kilian, L., \& Park, C. (2009). The impact of oil price shocks on the U.S. stock market. International Economic Review, 50(4), 1267-1287. https://doi.org/10.1111/j.1468-2354.2009.00568.x

Oberndorfer, U. (2009). Energy prices, volatility, and the stock market: Evidence from the Eurozone. Energy Policy, 37(12), 5787-5795. https://doi.org/10.1016/j.enpol.2009.08.043

Ozturk, I. (2010). A literature survey on energyy prices, vol. Energy Policy, 38(1), $340-349$. https://doi.org/10.1016/j.enpol.2009.09.024

Xu, Y., \& Malkiel, B. G. (2003). Investigating the Behavior of Idiosyncratic Volatility. The Journal of Business, 76(4), 613-645. https://doi.org/10.1086/377033

\section{Copyrights}

Copyright for this article is retained by the author(s), with first publication rights granted to the journal.

This is an open-access article distributed under the terms and conditions of the Creative Commons Attribution license (http://creativecommons.org/licenses/by/4.0/). 